\title{
A Study on the Bactericidal Efficiency of Selected Chemical Disinfectants and Antiseptics
}

\author{
L.P.Wijesinghe ${ }^{1}$ and T.K.Weerasinghe ${ }^{2}$
}

Antiseptics and disinfectants are used extensively in hospitals and other health care settings for a variety of topical and hard-surface applications. However, their antibacterial effectiveness is not always well declared by the manufacturers and consumers find it difficult to choose the right product according to their needs. Therefore, the aim of the present study was to evaluate the bactericidal effectiveness of selected disinfectants and antiseptics found in the local market. Three disinfectants and antiseptics (Dettol, Lysol and Chlorox) were assessed using phase 1, BS EN 1040; 1997, Chemical Disinfectants and Antiseptics, Basic bactericidal activity-Test method and requirements. The in vitro activity of these disinfectants and antiseptics against two challenge strains Staphylococcus aureus and Pseudomonas aeruginosa were analysed. All these disinfectants and antiseptics were tested at four different concentrations and three different contact times. Results showed that using double concentration than recommended use dilution of Lysol had a significant impact on killing both S. aureus and P. aeruginosa. Dettol achieved a 99.999\% killing of S. aureus within 5 minutes at the recommended use dilution and 15 minute contact time showed to be the best in achieving an effective killing of $P$. aeruginosa at the recommended use dilution. The results of Chlorox indicated that a 15 minute contact time was far more effective against $S$. aureus than 5 minute contact time specified by the manufacturer. Chlorox achieved a 99.999\% killing of $P$. aeruginosa within a contact time of 15 minutes at all concentrations tested. It revealed that the prolonged contact times increased the activity of Chlorox irrespective of the concentration used. At 1 minute contact time none of the products achieved a 5 log reduction against both $S$. aureus and $P$. aeruginosa. The overall results suggest that Chlorox was the best disinfectant against both $S$. aureus and $P$. aeruginosa at the recommended use dilution.

Antiseptics and disinfectants are used extensively in hospitals and other health care settings for a variety of topical and hard-surface applications. In particular, they are an essential part of infection control practices and aid in the prevention of nosocomial infections. Mounting concern over the potential for microbial contamination and infection risks in the food and general consumer markets have also led to increased usage of antiseptics and disinfectants by the general public. 
Antiseptics are biocides or products that destroy or inhibit the growth of microorganisms in or on living tissue (e.g. health care personnel hand washes and surgical scrubs); and disinfectants are similar but generally are products or biocides that are used on inanimate objects or surfaces. Disinfectants can be sporostatic but are not necessarily sporicidal (Johnston et.al, 2002).

A wide variety of active chemical agents (or "biocides") are found in antiseptics and disinfectants. Depending on the chemical nature of disinfectants and antiseptics they can be categorized into several groups. They are alcohols, phenolics, halogens, Quaternary Ammonium Compounds (QACs) and aldehydes. The mode of action of disinfectants and antiseptics differ greatly according to the chemical substance present. The choice of the disinfectant to be used depends on a particular situation. Some disinfectants have a wide spectrum (kill nearly all microorganisms), whilst others kill a smaller range of disease-causing organisms, but are preferred for other properties (they may be non-corrosive, non-toxic, or inexpensive) (Pelczar et.al 1993).

The basic principle now widely accepted is that, the antimicrobial efficiency of a disinfectant or an antiseptic is examined at three stages of testing (Pelczar et.al 1993).

The first stage concerns laboratory tests in which it is verified whether a chemical compound or a preparation possesses antimicrobial activity. For these preliminary screening tests, suspension tests are considered. In the second stage of tests, disinfection procedures and not disinfectants are examined. It is determined under which conditions and at which use-dilution for a given application the preparation is active: the tests simulate real-life situations; such tests are carrier tests for the disinfection of materials by submersion and surface disinfection tests. The last stage takes place in the field, and comprises the in-situ tests which examine whether, after a normal period of use, germs are still killed by the disinfectant solution.

There are many standards to follow in carrying out efficiency tests for disinfectants and antiseptics; American standards; European standards; ISO standards etc. In Sri Lanka the efficiency of disinfectants is tested using SLS 688:1985(Prescribe the requirements and methods of sampling and test for disinfectants). There are no Sri Lankan standards to test the efficiency of antiseptics. It is very important to test the efficiency of disinfectants and antiseptics before they are released for consumer use. Therefore, in this study, it is recommended that the efficacy test for the antiseptics and disinfectants must be carried out using British Standards as it includes test 
methods for both types. This research focuses on the first phase of the BS EN 1040; 1997, Chemical Disinfectants and Antiseptics, Basic bactericidal activity test method and requirements (Phase 1) (Anon,1997), to test the efficiency of selected disinfectants and antiseptics from the local market. This study would be a preliminary bench work to identify the importance of developing a local standard for antiseptics and also developing new standards for disinfectants.

\section{Types of disinfectants and antiseptics}

Alcohols are among the most widely used disinfectants and antiseptics. They are colourless hydrocarbons with one or more hydroxyl functional groups. Alcohols are bactericidal and fungicidal but not sporicidal. Some lipid containing viruses are also destroyed by alcohol (Prescott et.al , 2005). The two most popular alcohol germicides are ethanol and isopropanol usually used in about $70-80 \%$ concentration (Russel, 1981). The mode of action of alcohol depends upon its concentration. Alcohol with a concentration of $50 \%$ and higher dissolves membrane lipids, disrupts cell surface tension and compromises membrane integrity. An alcohol that has entered the protoplasm denatures protein through coagulation but only in alcohol-water solution of 50-95\%. Absolute alcohol (100\%) dehydrates cells and inhibits their growth (Block,1977). Some of its effectiveness as surface disinfectants can be attributed to its cleansing or detergent action, which helps in the mechanical removal of micro-organisms. Solutions of $70-95 \%$ alcohol are used as skin degerming agents. Most commonly used is ethanol (60-90\%), 1-propanol (60-70\%) and 2-propanol/isopropanol (70-80\%) or a mixture of these alcohols. They are commonly referred to as "surgical alcohol" which is used to disinfect the skin before injections. Ethyl alcohol is used to disinfect surgical instruments, face masks, thermometers etc. Alcohol effectively kills the Staphylococcus aureus (70\% Ethyl alcohol concentration in 10min), the Escherichia coli (70\% Ethyl alcohol concentration in $2 \mathrm{~min}$ ) and the Polio virus (70\% Ethyl alcohol concentration in 10min) (Prescott et.al, 2005).

Phenol was the first widely used antiseptic and disinfectant. Phenolics consist of one or more aromatic carbon rings with added functional groups. The three important substances are alkylated phenols (cresols), chlorinated phenols (chlorophene) and bisphenols (hexachlorophene) (Talaro \& Talaro, 1996). Phenolics are strongly microbicidal and will destroy vegetative bacteria, fungi and most viruses (not hepatitis B). However, they are not reliably sporicidal (Talaro \& Talaro, 1996). They may be either bacteriostatic or bactericidal, depending on the concentrations used. Modes of action of 
phenol depend on the concentrations used. In high concentrations they are cellular poisons, rapidly disrupting cell walls and membranes and precipitating proteins. They damage the cell wall by altering the normal selective permeability of the cytoplasmic membrane, causing leakage of vital intracellular substances. In lower concentrations they inactivate the critical enzyme system (Pelczar et.al,1993). Phenolics are active ingredients in some household disinfectants. They are also found in some mouthwashes and in disinfectant soap and hand washes. A 5\% aqueous solution of phenol is used for disinfecting drains and cesspools. Phenol is rather corrosive to the skin and sometimes toxic to sensitive people.

Halogens (iodine and chlorine) are important antimicrobial agents (Prescott et.al , 2005) Most halogens exert their antimicrobial effect primarily in the non-ionic state. They are highly effective components of disinfectants and antiseptics. Halogens are strong oxidizing agents. They are sporicidal with longer exposure. The major forms used in microbial control among chlorine compounds are liquid and gaseous chlorine, hypochlorites (OCl) and chloramines (NH2-Cl) ((Talaro \& Talaro, 1996). They destroy vegetative bacteria and fungi, but not their spores (Reybrouck, 1998). In solution these compounds combine with water and release hypochlorus acid $(\mathrm{HOCl})$, that oxidises the sulfhydryl $(\mathrm{S}-\mathrm{H})$ group on the amino acid cysteine, that interferes with the disulfide (S-S) bridges of numerous enzymes. The resulting denaturation of the enzymes is irreversible and suspends metabolic reactions (Talaro \& Talaro, 1996). Chlorine is used to disinfect swimming pools, and is added in small quantities to drinking water to reduce waterborne diseases. Chloramine is used presently in drinking water treatment instead of chlorine because it produces fewer disinfection byproducts. Hypochlorites (Sodium hypochlorite), often in the form of common household bleach, are used in the home to disinfect drains, and toilets. Sodium hypochlorite is the principal ingredient in Chlorox which is a household disinfectant and a bleaching agent. Hypochlorites yield an aqueous solution of hypochlorous acid that is the true disinfectant. Chlorine and its compounds effectively kills the Staphylococcus (5\% Sodium hypochlorite), the Mycobacterium tuberculosis (50ppm chlorine in $50 \mathrm{sec})$, the Entamoeba cysts $(0.1 \mathrm{ppm}$ chlorine in $150 \mathrm{~min})$ and the Hepatitis A virus (3ppm chlorine in $30 \mathrm{~min})$ ( (Talaro \& Talaro ,1996). Iodine compounds have the broadest spectrum of all topical antiinfectives with action against bacteria, fungi, viruses, spores, protozoa and yeast. Iodine is used mainly as a skin antiseptic. Iodine rapidly penetrates the cells of micro-organisms where it apparently disturbs a variety of metabolic functions by interfering with disulfide bonds of 
protein. It also iodinates cell proteins.

Quaternary Ammonium Compounds(QAC) have positively charged quaternary nitrogen and a long chain hydrophobic aliphatic chain ((Prescott et.al, 2005). They are used as low level disinfectants (Russel, 1981). If used in medium concentrations, they are effective against some Gram-positive bacteria, viruses, fungi and algae. In low concentrations, they have microbistatic effect. QACs are ineffective against the tubercle bacillus, the hepatitis virus, Pseudomonas and spores at any concentration ((Talaro \& Talaro ,1996). QACs lower cellular surface tension. This can have several effects but chief among them is the disruption of the cell membrane and the loss of its selective permeability. QACs kill micro-organisms by causing a leakage of microbial protoplasm, precipitating proteins and inhibiting metabolism (Talaro \& Talaro,1996). Benzalkonium chloride is used in hand scrubs and face washes. It is also used in some pre-operative skin disinfectants (conc. $0.05-0.5 \%$ ) and antiseptic towels. Benzalkonium chloride is the principal ingredient in Lysol, a household disinfectant. Cetylpyridinium chloride is used to disinfect food utensils and as a skin antiseptic. QACs effectively kill the Staphylococcus aureus (450ppm of QACs in $10 \mathrm{~min}$ ) and the Salmonella typhi (300ppm of QACs in $10 \mathrm{~min}$ ) (Russel, 1981).

Organic substances bearing a formyl (-CHO) functional group on the terminal carbon are called aldehydes. Two aldehydes used most often in microbial control are glutaraldehyde and formaldehyde.

Glutaraldehyde is a yellow acid liquid with a mild odour. It is a rapid, broad spectrum antimicrobial chemical and is officially accepted as a steriliant and high level disinfectant. It kills spores in 3 hours and fungi and vegetative bacteria (even Mycobacterium and Pseudomonas) in a few minutes. Viruses including the most resistant forms appear to be inactivated after relatively short exposure times. They cross link protein molecules on the cell surface through alkylation of amino acids, a process in which a hydrogen atom on an amino acid is replaced by the glutaraldehyde molecule itself. It can also irreversibly disrupt the activity of enzymes within the cell. A $2 \%$ buffered solution of glutaraldehyde is used to disinfect hospital and laboratory equipment ((Talaro \& Talaro ,1996). Glutaraldehyde effectively kills the Staphylococcus aureus( $2 \%$ glutaraldehyde in $<1$ minute), the Mycobacterium tuberculosis ( $2 \%$ glutaraldehyde in $<10$ minute) and the Herpes simplex virus ( $2 \%$ glutaraldehyde in $<10$ minute). 


\section{Disinfectant and antiseptic test methods}

All disinfectant and antiseptic tests have the same final purpose of measuring the antimicrobial activity of a chemical substance or preparation. Over the past few years a large number of test methods have been developed to check the efficiency of disinfectants and antiseptics. They are subdivided into suspension tests, carrier and surface disinfection tests and other practice-mimicking tests (Reybrouck, 1998). The suspension tests comprise qualitative and quantitative suspension tests, and, as derived tests, the determination of the phenol coefficient and capacity tests.

The simplest disinfectant tests are the suspension tests. They all have the following features in common; an appropriate volume of bacterial suspension, the inoculum, is added to the disinfectant in the concentration to be tested. After a given exposure time, a sample is examined to determine whether the inoculum has been killed or not. Initially this was done in a qualitative way. A loopful of bacterial suspension was brought into contact with the disinfectant and again a loopful of this mixture was cultured for surviving organisms. Results were expressed as 'growth' (+) or 'no growth' ( - ). At present the number of surviving organisms is counted and compared to the original inoculum size. By subtracting the logarithm of the former from the logarithm of the latter, the decimal log reduction or microbicidal effect (ME) is obtained. An ME of 1 equals to a killing of $90 \%$ of the initial number of bacteria, an ME of 2 means $99 \%$ killed. A generally accepted requirement is an $\mathrm{ME}$ that equals or is greater than 5: at least 99.999\% of the germs are killed. Several concentrations and exposure periods can easily be examined. A quantitative suspension test is the basic test in all contemporary testing schemes. It is examined in these suspension tests whether microorganisms are killed by a disinfectant in terms of a range of concentrations and several times of exposure. There is an intense contact between the disinfectant solution and the bacterial cells. As a result these tests are generally well standardized ((Russel, 1981)

Much research has been carried out to study the effectiveness and efficiency of disinfectants and antiseptics (Payne et al. 1998)

\section{Neutralizers}

A neutralizer is an agent which posses the ability to quench the action of a disinfectant or an antiseptic. An effective neutralizer must satisfy the following criteria. First, the neutralizer must effectively inhibit 
the action of the biocidal solution. Second, the neutralizer must not itself be unduly toxic to the challenge organisms. Finally, the neutralizer and active agent must not combine to form a toxic compound.

In early studies of disinfection, efficacy was over estimated due to poor, or no, neutralization of the disinfectant after a specified time of exposure to the bacteria (Langsrud and Sundheim 1998, as quoted in Johnston et al.2001). Russell et al. (1981) stated that a failure to distinguish adequately the bacteriostatic and bactericidal effects has been responsible for inaccurate conclusions, notably with QACs. Compounds with high dilution coefficients rapidly lose their activity on dilution. However, it is not always known whether this is sufficient to remove the disinfectant bound to a viable cell. For this reason the incorporation of an appropriate neutralizing agent is incorporated, as well as dilution is recommended (Russel, 1981).

Johnston et al. (2002) showed that a combination of a Universal Quenching Agent (UQA) and dilution was effective at halting the action of all biocides tested, except phenyl mercuric acetate (PMA).

\section{Test Organisms}

In most disinfectant test methods the Staphylococcus aureus and the Pseudomonas aeruginosa are used as test organisms. S.aureus is a Gram-positive, facultative anaerobic coccus. The optimum temperature for growth is $37^{\circ} \mathrm{C}$, but it can grow anywhere between $10^{\circ} \mathrm{C}$ to $46^{\circ} \mathrm{C}$. It can digest protein and lipids and ferment a variety of sugars (Block, 1977). S. aureus may occur as a commensal on human skin (particularly the scalp, armpits and groins); it also occurs in the nose (in about $25 \%$ of the population) and throat and less commonly, may be found in the colon and in the urine. It can survive on domesticated animals such as dogs, cats and horses. It can survive for some hours on dry environmental surfaces. S.aureus causes many diseases including boils and abscesses on skin, impetigo and food poisoning (Block, 1977). This species is considered the most resistant of all non spore forming pathogens, with well developed capacities to withstand high salt (7.5-10.0\%), extremes in $\mathrm{pH}$, and high temperatures (up to $60^{\circ} \mathrm{C}$ for 60 minutes). It also remains viable after months of air drying, and resists the effects of many disinfectants and antibiotics. These properties contribute to the reputation of $S$. aureus as a troublesome hospital pathogen ((Talaro \& Talaro, 1996). 
$P$. aeruginosa is a Gram-negative, aerobic, rod-shaped bacterium with unipolar motility (Block, 1977). These bacteria are common inhabitants of soil and water. They occur regularly on the surfaces of plants and occasionally on the surfaces of animals. It is an opportunistic pathogen on both humans and plants. An opportunistic pathogen is an organism which exploits some break in the host's defences to initiate an infection. It causes urinary tract infections, respiratory system infections, dermatitis, soft tissue infections, bone and joint infections, gastrointestinal infections and a variety of systemic infections, particularly in patients with severe burns and in cancer and AIDS patients who are immunosuppressed. The P.aeruginosa infection is a serious problem in patients hospitalized with cancer, cystic fibrosis, and burns (Russel, 1981). It is very resistant to antiseptics and disinfectants. Therefore, it is considered a significant hospital pathogen.

New disinfectants and antiseptics are continuously being released to the market. Currently there are a large number of disinfectants and antiseptic products in the local market. However, their antibacterial effectiveness is not always well declared by the manufacturers. Therefore consumers find it difficult to choose the right product according to their needs. Sometimes consumers prefer to buy cheaper products without considering the antibacterial efficiency of the product. In the Sri Lankan context there is no proper control over disinfectants and antiseptics that are released to the market. It is necessary to standardize disinfectants and antiseptics before releasing them for consumer use.

This research project was initiated to test the efficiency of disinfectants and antiseptics found in the local market. Disinfectant and antiseptic products representing various chemical groups were selected and evaluated for their antibacterial activity during various test concentrations and contact times. This selection within a particular type was based on consumer usage in the open market. Recommended "use dilutions" of products were tested to check whether they actually possess the antibacterial activity declared by the manufacturer.

The main objective of this study was to test the bactericidal efficiency and effectiveness of chemical disinfectants and antiseptics found in the local market against the Staphylococcus aureus and the Pseudomonas aeruginosa. The study also aimed at finding out the most appropriate neutralizing agent between the phosphate buffer and the universal quenching agent, the efficiency of Dettol, Lysol and Chlorox against the Staphylococcus aureus and the Pseudomonas aeruginosa, the accuracy of the manufacturer's recommended use dilutions and to identify 
which type of disinfectant and antiseptic among Dettol, Lysol and Chlorox has the most bactericidal effect against these organisms.

Disinfectants and antiseptics representing the soluble phenolics (Dettol), the Quaternary Ammonium Compounds (Lysol) and the Halogen (Chlorox) groups were assessed using phase 1, BS EN 1040; 1997, Chemical Disinfectants and Antiseptics, Basic bactericidal activity- Test method and requirements Phase 1. DilutionNeutralization methods described in the standard was followed. The in vitro activity of these disinfectants and antiseptics against two challenge strains the Staphylococcus aureus and the Pseudomonas aeruginosa were analysed. All these disinfectants and antiseptics were tested four different concentrations. At 50\% concentration, 2 times the recommended use dilution, recommended use dilution (stated on the cover of each disinfectant and antiseptic) and 0.5 times recommended use dilution. They were tested at 1,5 and 15 minute contact times. Eight replicates were done for each testing time.

Before starting the test, all reagents were equilibrated to $20^{\circ} \mathrm{C}$ in a water-bath. An $8.0 \mathrm{ml}$ of test product solution was added to $1.0 \mathrm{ml}$ of sterile water. Then $1.0 \mathrm{ml}$ of the bacterial test suspension containing $1.5 \times 10^{8}$ to $5 \times 10^{8} \mathrm{cfu} / \mathrm{ml}$ was added, vortexed to mix, and was kept in a $20^{\circ} \mathrm{C}$ water bath. 1,5 and 15 minutes after the addition of the bacterial test suspension, $1 \mathrm{ml}$ was removed and added to $8.0 \mathrm{ml}$ neutralization medium to which $1.0 \mathrm{ml}$ sterile water had been added, mixed by vortexing, and left at $20^{\circ} \mathrm{C}$. After 5 min neutralization time, duplicate $1.0 \mathrm{ml}$ volumes were pour plated with tryptone soya agar and incubated at $37^{\circ} \mathrm{C}$ for $48 \mathrm{hr}$ prior to counting. The microbicidal effect (ME) was calculated by subtracting the log of viable count after disinfection $(\mathrm{Na})$ from the log of the initial count in the bacterial test

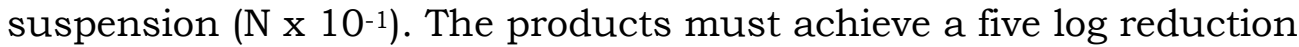
in viable counts ( $\mathrm{ME}$ value of 5 or higher) to accept as a microbicidal compound.

For all the products, preliminary tests were carried out to confirm the efficacy of the neutralization medium used in the study. The filter strip method was carried out to ascertain the efficacy of the neutralizer. The phosphate buffer and the Universal Quenching Agent (UQA) were tested. The study confirmed that UQA was more suitable as the neutralizer. 
Calculation of weighted mean count (in $\mathrm{cfu} / \mathrm{ml}$ ) in bacterial test suspension (N)

$$
\mathrm{N}=\frac{c}{\left(n_{1}+0.1 n_{2}\right) d}
$$

$c=$ sum of the colonies counted on all the plates.

$\mathrm{n}_{1}=\quad$ sum of the number of plate taken into account at the $1^{\text {st }}$ dilution

$\mathrm{n}_{2}=\quad$ sum of the number of plate taken into account at the $2^{\text {nd }}$ dilution

$\mathrm{d}=$ the dilution factor corresponding to the 1 st dilution taken in to account

\section{Calculation of viable counts (in $\mathrm{cfu} / \mathrm{ml}$ ) in test mixture $\left(\mathrm{N}_{\mathrm{a}}\right)$}

$$
\begin{aligned}
& \mathrm{N}_{\mathrm{a}}=\frac{c}{n \times d \times v} \\
& \mathrm{c}=\text { sum of the colonies counted on both plates. } \\
& \mathrm{n}=\text { number of plates taken into account } \\
& \mathrm{d}=\quad \begin{array}{l}
\text { dilution factor corresponding to the dilution taken } \\
\text { into account }
\end{array} \\
& \mathrm{v}=\text { sample volume }
\end{aligned}
$$

\section{Microbicidal Effect (ME)}

For each test organism and product test concentration the reduction in viability (in $\mathrm{cfu} / \mathrm{ml}$ ) was calculated as follows:

Reduction in viability $=\frac{N \times 10^{-1}}{N_{a}}$

$\mathrm{N}=\quad$ Number of $\mathrm{cfu} / \mathrm{ml}$ in bacterial test suspension 
$\mathrm{N}_{\mathrm{a}}=\quad$ Number of $\mathrm{cfu} / \mathrm{ml}$ in the test mixture

For each test organism and product test concentration the Microbicidal Effect was calculated as follows:

$$
\text { Microbicidal Effect }(\mathrm{ME})=\log N \times 10^{-1}-\log
$$

To pass the test, products must achieve at least an ME value of 5 . It is a 5 - $\log$ reduction in viable counts. (A 5-log reduction means a reduction in the number of microorganisms by 100,000-fold.)

$$
\begin{aligned}
& \text { ME } 5 \text { = Pass (Achieves a 99.999\% killing of germs) } \\
& \mathrm{ME}<5 \text { = Fail (Fails to achieve a } 99.999 \% \text { killing of germs) }
\end{aligned}
$$

\section{Statistical Analysis}

Statistical packages (Minitab new version version 11.12/SPSS version 11.01) were used to analyze the $\mathrm{ME}$ values statistically.

Student $T$ tests were carried out for independent samples to find the significant effect of a particular disinfectant for test organisms (S.aureus and P.aeruginosa) with regard to the Mean ME values.

$\mathrm{H}_{0^{-}}$Mean ME values of S.aureus and P.aeruginosa for a particular disinfectant are equal. (For a single disinfectant $\mathrm{ME}_{\text {S.aureus }}=\mathrm{ME}_{\text {P.aeruginosa) }}$

$\mathrm{H}_{1}$ - Mean ME values of S.aureus and P.aeruginosa for a particular disinfectant are equal. (For a single disinfectant $\mathrm{ME}$ S.aureus $^{\neq}=\mathrm{ME}_{\text {P.aeruginosa) }}$

If $\mathrm{P}$ value given by $\mathrm{T}$ test is less than 0.05 then $\mathrm{HO}$ was rejected. Therefore it can be concluded that $\mathrm{ME}$ value of a particular disinfectant against the two organisms were significant at 5\% significant level.

One sample $\mathrm{T}$ tests were carried out to find the significant effect of a particular disinfectant for the two test organisms at their recommended use dilutions.

$$
\begin{aligned}
& \mathrm{H}_{0}-\text { Mean } \mathrm{ME} \text { value }=5 \\
& \mathrm{H}_{1}-\text { Mean } \mathrm{ME} \text { value }<5
\end{aligned}
$$


If $\mathrm{P}$ value given by One sample $\mathrm{T}$ test was less than 0.05 then $\mathrm{H}_{0}$ was rejected. It can be concluded that Mean ME value of a disinfectant at the recommended use dilution is less than 5 .

Figure 1: $\quad$ The Microbicidal Effect of Lysol against (a) S. aureus (b) $P$. aeruginosa at different concentrations and contact times
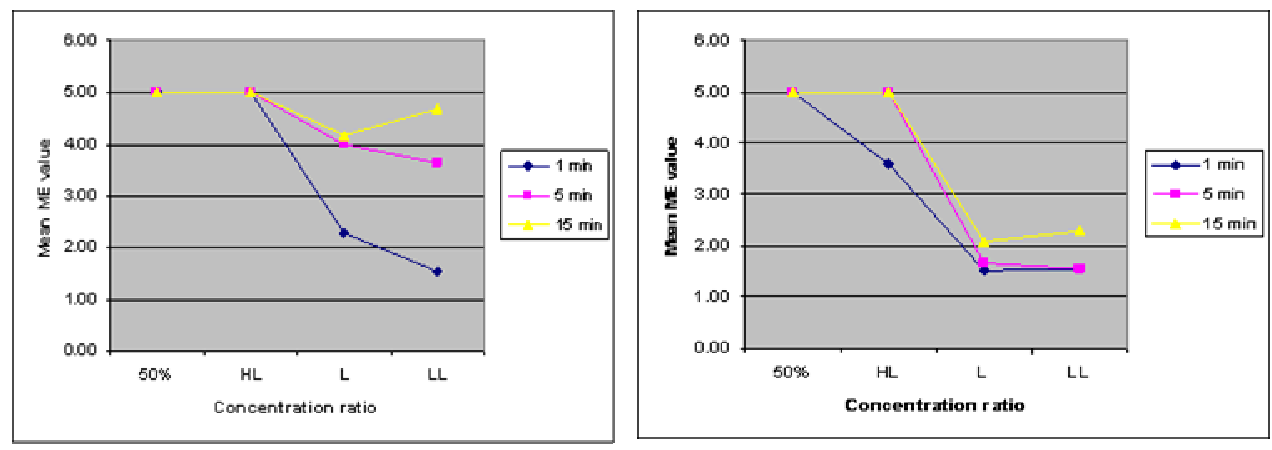

HL- $\quad$ x 2.0 times disinfectant recommended use dilution, $\mathrm{L}-\mathrm{x} 1.0$ times disinfectant recommended use dilution,

LL- $\quad$ x 0.5 times disinfectant recommended use dilution

** The ME value indicated as 5.00 in the graph could be 5 or greater than 5 .

Figure 2: $\quad$ The Microbicidal Effect of Dettol against (a) S. aureus (b) $P$. aeruginosa at different concentrations and contact times
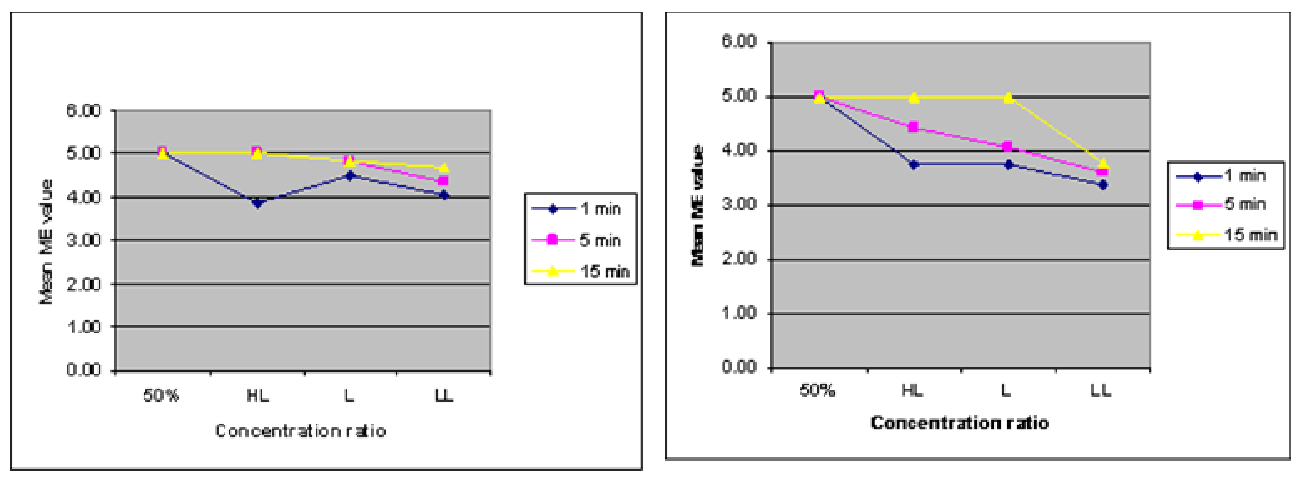

HL- $\quad$ x 2.0 times disinfectant recommended use dilution, $L-x 1.0$ times disinfectant recommended use dilution,

LL- $\quad$ x 0.5 times disinfectant recommended use dilution

** The ME value indicated as 5.00 in the graph could be 5 or greater than 5 . 
Figure 3: $\quad$ The Microbicidal Effect of Chlorox against (a) S. aureus (b) $P$. aeruginosa at different concentrations and contact times
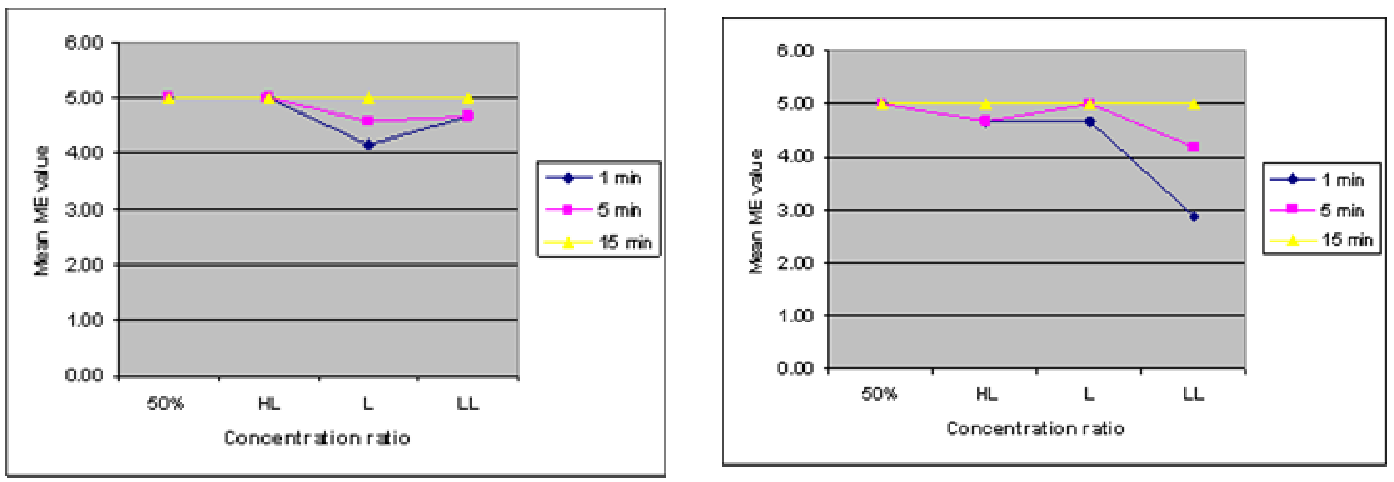

HL- x 2.0 times disinfectant recommended use dilution, L $-\mathrm{x} 1.0$ times disinfectant recommended use dilution,

LL- x 0.5 times disinfectant recommended use dilution

** The ME value indicated as 5.00 in the graph could be 5 or greater than 5 .

The results of the present study showed that even a contact time of 15 minutes was insufficient for an effective killing (99.999\%) of the S. aureus (Figure 1a). A contact time of 10 minutes and the recommended use dilution specified by the manufacturer was not sufficient for effectively killing the $P$. aeruginosa (Figure $1 \mathrm{~b}$ ). The results showed that using a double concentration rather than the recommended use dilution of Lysol had a significant impact on killing both the $S$. aureus and the $P$. aeruginosa. Dettol achieved a $99.999 \%$ killing of the $S$. aureus within 5 minutes at the recommended use dilution (Figure 2a). A 15 minute contact time was the best in achieving an effective killing of the $P$. aeruginosa at the recommended use dilution (Figure 2b). The results of Chlorox indicated that a 15 minute contact time was far more effective against the $S$. aureus than a 5 minute contact time specified by the manufacturer (Figure 3a). Chlorox achieved a 99.999\% killing of the $P$. aeruginosa within a contact time of 15 minutes in all concentrations tested (Figure 3b). It revealed that prolonged contact times increased the activity of Chlorox irrespective of the concentration used. At 1 minute contact time none of the products achieved a $5 \log$ reduction against both the $S$. aureus and the $P$. aeruginosa.

The statistical evaluations also revealed that for the recommended use dilutions of the products, only Chlorox achieved a ME value of 5 within 15 minute contact time, against both the $S$. aureus and the $P$. 
aeruginosa, at 5\% significant level. Both Lysol and Dettol failed to achieve an $\mathrm{ME}$ value of 5, against either of the test organisms at their recommended use dilutions and a contact time of 15 minutes, at 5\% significant level.

There were significant differences $(\mathrm{p}<0.05)$ between the microbicidal activities of Lysol and Dettol against the $S$. aureus and the $P$. aeruginosa. However, there was no significant difference $(\mathrm{p}>0.05)$ between the microbicidal activities of Chlorox against the $S$. aureus and the $P$. aeruginosa. Results indicated that Lysol and Dettol were more effective against $S$. aureus.

The overall results suggest that Chlorox was the best disinfectant against both the $S$. aureus and the $P$. aeruginosa at the recommended use dilution.

\section{References:}

Anon(1997) BS EN 1040; Chemical disinfectants and antiseptics, Basic bactericidal activity-test method and requirements (Phase 1), London; British Standards Institution.

Block, S.S.(1977); Disinfection, Sterilization and Preservation; 2nd Edition; Lea $\&$ Febiger $(3, \mathrm{~K}, \mathrm{p} 30)$.

Espigares,E; Bueno,A; Fernandez-Crehuet M; Esprages m;(2003); Journal of Hospital Infection 55, 137-140.

Johnston,M.D; Lambert,R.J.W; Hanlon,G.W.; and Denyer,S.P;(2002); A rapid method for assessing the suitability of quenching agents for individual biocides as well as combinations; Journal of Applied Microbiology 92, 784-789.

McDonnell,G; Russell, D;(1999); Antiseptics and Disinfectants: Activity, Action and Resistance; Clinical Microbiology Reviews, v, 12(1), 147-179

Pelczar,M.J; Chan E.C.S; Kleig N.R.;(1993) 1st Edition; McGraw Hill Inc; Microbiology Concepts and Applications; 221-237

Prescott,L.M. ; Harley,J.P.; Klein,A.K.;(2005); Microbiology; 6th Edition; McGraw Hill; 134-146

Reybrouck, G (1998); The testing disinfectants; International Biodeterioration and Biodegradation, 41, 269-272. 
Russel, A.D;(1981); Neutralization Procedures in the evaluation of bactericidal activity. In Disinfectants, Their use and Evaluation of Effectiveness, S.A.B.Technical series; 16th Edition; Collins, C.H; Allwood M.C; Bloomfield and Fox, A; London: Academic Press; 45-49

Talaro K \& Talaro A(1996): Foundation in Microbiology; 2nd Edition,Wm.C.Brown Publishers,U.S.A. pp 30-77. 